\title{
Osteoporoz ile Takipli Hastalarda Gelișen Kalça Kırığı Sıklığının Değerlendirilmesi
} Evaluation of Hip Fracture Frequency in Patients with Osteoporosis

\author{
${ }^{1}$ Merih Özgen, ${ }^{1}$ Zeliha Atik, ${ }^{1}$ Onur Armağan, ${ }^{2}$ Fezan Mutlu \\ ${ }^{1}$ Eskişehir Osmangazi Üniversitesi Tıp Fakültesi, Fizik Tedavi ve Rehabilitasyon Anabilim Dalı, \\ Eskişehir, Türkiye \\ ${ }^{2}$ Eskişehir Osmangazi Üniversitesi Tıp Fakültesi, Biyoistatistik Anabilim Dalı, Eskişehir, Türkiye
}

\begin{abstract}
Özet: Osteoporoz dünyada yaygın görülen önemli bir sağlık sorunudur. Osteoporoza bağlı kalça kırıkları önemli bir mortalite ve morbidite sebebidir. Bu çalışmanın amacı; kliniğimizde takipli osteoporoz hastalarındaki kalça kırı̆̆ı sıklığını belirlemektir. Ocak 2009 - Aralık 2010 tarihleri arasında polikliniğimize başvuran osteoporoz tanısı ile takipli hastaların dosyaları retrospektif olarak tarandı. Aralık 2018'e kadar geçen sürede kalça kırı̆̆ı geçiren hastaların sosyodemografik özellikleri (yaşı, cinsiyeti), tanıları (postmenopozal osteoporoz, premenopozal osteoporoz, erkek osteoporozu, sekonder osteoporoz), kalça kırı̆̆ı dışında başka kırık geçirip geçirmedikleri dosya bilgilerinden ve telefonla sorgulanarak elde edildi. Osteoporotik kalça kırığı ile ilişkili ölümler değerlendirildi. Osteoporoz tanısı olan 286 hasta dosyası incelendi. Hastaların 147'si çalıșmaya dâhil edildi. Hastaların \% 8,84 $(n=13)$ 'ünde kalça kırığı tespit edildi. Osteoporoz hastalarında kalça kırığına bağlı ölüm oranı \% 2,04 (n=3) 'dü. On üç hastanın 10'unda kalça kırığı haricinde farklı bölgede (vertebra, kol, ön kol) kırık mevcuttu. Takipli osteoporoz hastalarındaki kalça kırı̆ğ sıklığı ve buna bağlı ölümlerin oranı belirlenmiştir. Sonuçlarımızın mevcut veri tabanına katkı sağlayacağı ve farkındalığı arttıracağı düşünülmüştür.
\end{abstract}

Anahtar Kelimeler: osteoporoz, kalça kırı̆̆ı

Abstract: Osteoporosis is a common health problem in the world. Hip fractures due to osteoporosis are an important cause of mortality and morbidity. The aim of this study was to determine the frequency of hip fracture in patients with osteoporosis. The files of patients with osteoporosis who admitted to our clinic between January 2009 and December 2010 were analyzed retrospectively. Between January 2009- December 2018, the patients who had hip fracture were determined by patient file and by telephone. Their sociodemographic features (age, sex), diagnoses (postmenopausal osteoporosis, premenopausal osteoporosis, male osteoporosis, secondary osteoporosis) and other fractures except hip were recorded. Osteoporotic hip fracture-related deaths were evaluated. 286 patients with osteoporosis were evaluated. 147 patients were included in the study. Hip fracture was detected in 8,84 $\%(\mathrm{n}=13)$ of the patients. The mortality rate related to hip fracture in patients with osteoporosis was $2.04 \%(\mathrm{n}=3)$. In 10 out of 13 patients who had hip fracture, fracture was observed in different areas except hip fracture (vertebra, arm, forearm). The frequency of hip fracture and related mortality in osteoporosis patients followed by our clinic were determined.It is thought that our results will contribute to existing database and increase the awareness.

Keywords: osteoporosis, hip fracture

ORCID ID of the authors: M.O. 0000-0002-8919-968X; Z.A. 0000-0001-7111-3529; O.A. 0000-0002-5917-5839; F.M. 0000-0002-9339-4031 


\section{Giriș}

Osteoporoz, düşük kemik kütlesi ve kemik dokusunun mikro-mimarisindeki bozukluk sonucu kemik kırılganlığında artma ile karakterize progresif bir metabolik kemik hastalığıdır (1). Dünyada insan yaşamının uzaması sonucunda yaşlı nüfusun artması osteoporozu önemli bir sağlık sorunu haline getirmiştir (2).

Osteoporoza bağlı gelişen kırıklar mortalite, mobidite ve yüksek maliyete yol açar (3). Osteoporotik kırıklar, frajilite kırığıdır ve normalde kırık oluşturmayacak düzeydeki düşük düzeyli ve/veya düşük enerjili mekanik güçler sonucunda oluşur (4). Osteoporoza bağlı gelişen kırıklarda en önemli risk faktörü azalmış kemik yoğunluğu olmakla birlikte, yaş, cinsiyet, geçirilmiş kırık hikâyesi, ailede osteoporoz öyküsünün olması, sistemik ilaç kullanımı, fazla alkol ve sigara kullanımı da diğer risk faktörleri arasındadır $(1,5)$.

Osteoporotik kırıklar en çok vertebral kolon, kalça, el bileği ve omuzda görülür (4). Kalça kırığı, en yüksek morbidite oranına sahiptir ve osteoporozun mevcut maliyetini önemli ölçüde arttırır. Kalça kırığının hastanedeki tedavisi, sonraki rehabilitasyonu ve ortaya çıkan ev ihtiyaçları göz önünde bulundurulduğunda, toplumsal yük ve sağl1k ekonomisine etkileri büyüktür (6). Kalça kırı̆̆ı, geçiren hastaların yaklaşık \% 20'si kalça kırığını takiben ilk yıl içinde ölmektedir. Bu nedenle kalça kırı̆ğ osteoporozun en ciddi sonucudur (7).

Yaşam süresinin ve yaşlı nüfusun artması nedeniyle osteoporoza bağlı kırık sayısının daha da artması beklenmektedir (8). Dünya çapında kalça kırığı sayısının, 2025 yılına kadar yaklaşık iki kat, 2050 yılına kadar üç kattan fazla artacağı tahmin edilmektedir (9). Türkiye hala Avrupa'da düşük kalça kırığı oranına sahip bir ülke olmakla birlikte, son 20 yılda insidans belirgin olarak artmıştır. FRACTURK çalışmasında Türkiye'de 2009'da tahmini kalça kırığı sayısı 24,000/yıl iken, $2035^{\prime}$ 'de beklenen 64,000/y1l olarak bildirilmiştir (10).
Çalışmamızın amacı; kliniğimizde takipli osteoporoz hastalarındaki kalça kırığı sıklığını belirleyerek, mevcut veri tabanına katk1 sağlamak ve farkındalı̆̆ artırmaktır.

\section{Gereç ve Yöntem}

$\mathrm{Bu}$ çalışmada Eskişehir Osmangazi Üniversitesi Tıp Fakültesi, Fiziksel Tıp ve Rehabilitasyon Anabilim Dal1, Osteoporoz Polikliniği ' ne Ocak 2009 - Aralık 2010 tarihleri arasında başvuran osteoporoz tanısı alan ve takipli hastalar dâhil edildi. Hastaların dosyaları retrospektif olarak tarandı. Aralık 2018'e kadar geçen sürede kalça kırığı geçirenler ve kalça kırığına bağlı ölümler kaydedildi. $\mathrm{Bu}$ sürede farklı merkezlerde kalça kırığ 1 nedeniyle takip edilenlerin olabileceği düşünülerek hastalar telefonla arandı. Telefonla aranan hastalara öncelikle çalışmayla ilgili bilgi verildi ve kalça kırığ 1 geçirip geçirmedikleri soruldu.

Verileri tam olan ve ulaşılabilen hastaların sosyodemografik özellikleri (yaşı, cinsiyeti), tanıları (postmenopozal osteoporoz, premenopozal osteoporoz, erkek osteoporozu, sekonder osteoporoz), kalça kırığ 1 dışında başka kırık geçirip geçirmedikleri dosya bilgilerinden ve telefonla sorgulanarak elde edildi.

Glukortikoid fazlalığı (endojen, eksojen), hipogonadizm, bilinen endokrin veya neoplastik hastalığ 1 (romatoid artrit, ankilozan spondilit, cushing sendromu, hipertiroidizm, kemik metastazı vs.) olanlar sekonder osteoporoz grubunda yer ald1. Bu grubun dışında kalan osteoporoz tanısı alan kadınlar menopoz durumuna göre pre ve postmenopozal osteoporoz, erkekler ise erkek osteoporozu grubunda yer aldi.

Etik kurul onayı Eskişehir Osmangazi Üniversitesi Tıp Fakültesi Etik Kurulu'nun 25403353-050.99-E.119288 say1l 2018-263 kararı ile alınmıştır. 


\section{İstatistiksel analiz}

Sürekli değişkenler ortalama \pm standart sapma ve kategorik değişkenler frekans ve yüzde şeklinde gösterildi. Tanımlayıcı istatistikler SPSS 21.0 (SPSS Inc., Chicago, Illınois, US) paket programiyla elde edildi.

\section{Bulgular}

Ocak 2009 - Aralık 2010 tarihleri arasında osteoporoz tanis1 olan 286 hasta dosyas incelendi. Hastaların 139'una ulaşılamadı. Dosya verileri tam olup ulaşılan 147 hasta çalışmaya dâhil edildi. Çalışmaya dâhil edilen 147 hastanın 12'sinin öldüğü, 3'ünün kalça kırı̆̆ına bağlı öldüğü saptandı. Kalan 9 hastanın ölüm nedenleri arasında malignite, kalp yetmezliği, kronik karaciğer hastalığ kronik böbrek yetmezliği, miyokard infarktüsü, serebrovasküler olay gibi hastaliklar bulunmaktayd.

Çalışmaya dâhil edilen osteoporoz tanılı 147 hastanın 124'ü kadın (\%84.35), 23'ü erkekti $(\% 15,65)$. Yaş ortalamaları $60.93 \pm 9.40 \mathrm{idi}$.

Osteoporozlu 147 hastanın Ocak 2009-Aralık 2018 arasındaki takibinde osteoporoza bağlı 13 kalça kırığı vakası tespit edildi. 13 kalça kırığının 9'u kadın, 4'ü erkekti. 9 kadından 6's1 hayatta iken, 3'ü kalça kırığı sonrası ölmüştü (Şekil 1).

Osteoporoza bağl1 kalça kırı̆̆ 1 oranı \%8.84 olarak belirlendi (\%69.23 kadın, \%30.76 erkek). Osteoporoz hastalarında kalça kırığına bağlı ölüm oranı \%2.04'tü.

147 hastanın osteoporoz tipleri ve o dönemki yaş ortalamaları ayrıntılı olarak tablo 1'de gösterilmiştir.

Kalça kırı̆̆ı geçiren 13 hastanın kırık geçirdikleri yaş ortalaması $67.85 \pm 10.88$ idi. 13 hastanın 10'unda öz geçmişlerinde kalça kırığı haricinde osteoporoza bağlı farklı bölge (vertebra, kol, ön kol) kırıkları vardı (Tablo 2). Kalça kırığı geçiren hastaların kırık analizi tablo 3'te gösterilmiştir.

Kalça kırığına bağlı ölen 3 hastanın ikisi 87 ve 81 yaşlarında (2018), biri 78 yaşındayd 1 (2016). Bu hastaların daha önce vertebral kırığı olduğu gözlendi.

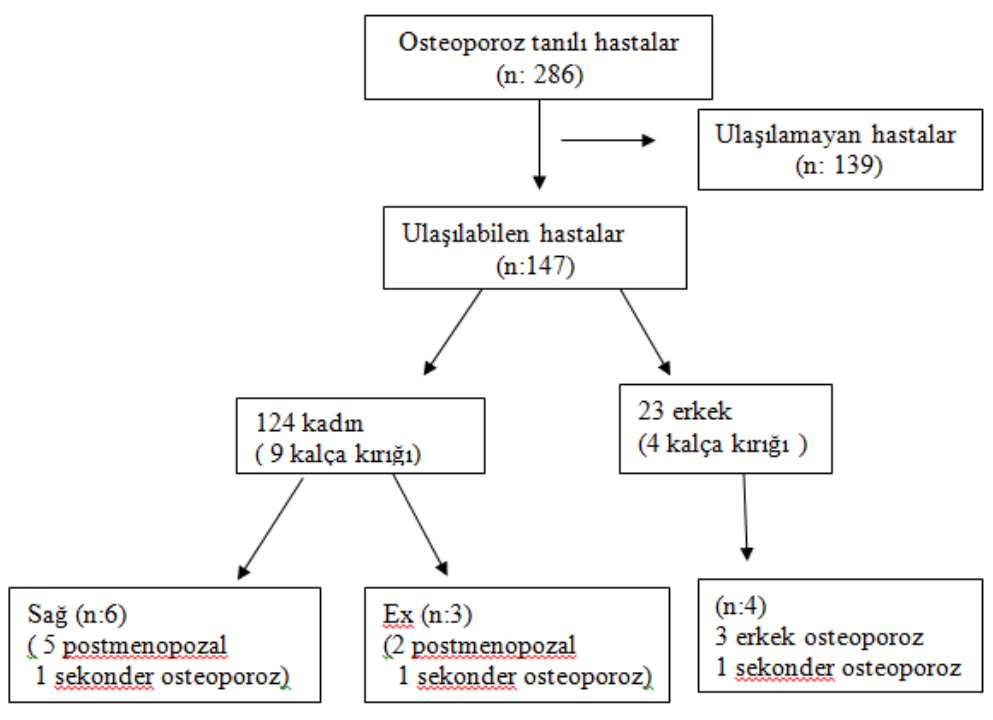

Şekil 1. Değerlendirme akış şeması 
Tablo 1. Osteoporoz Tiplerine Göre Dağılım ve Yaş Ortalamaları

\begin{tabular}{lcc}
\hline & & \\
\multirow{2}{*}{$\begin{array}{c}\text { Cinsiyet } \\
\text { Kadın }\end{array}$ Esteoporoz Tanılı Hastalar (N:147) } \\
\cline { 2 - 3 } \multicolumn{1}{c}{ Erkek } & $124(\% 84.35)$ & Yaş \\
\hline Premenopozal osteoporoz & $23(\% 15.65)$ & $59.93 \pm 9.35$ \\
Postmenopozal osteoporoz & $92(\% 5.44)$ & $66.30 \pm 7.81$ \\
Erkek osteoporoz & $16(\% 10.88)$ & $47.13 \pm 8.72$ \\
Sekonder osteoporoz & $31(\% 21.09)$ & $61.28 \pm 8.29$ \\
\hline
\end{tabular}

Tablo 2. Gruplara Göre Kalça Kırı̆̆ına Eşlik Eden Başka Kırık Varlığının Değerlendirilmesi

\begin{tabular}{lccc}
\hline & $\begin{array}{c}\text { Postmenopozal } \\
\text { Osteoporoz }\end{array}$ & $\begin{array}{c}\text { Erkek } \\
\text { Osteoporoz }\end{array}$ & $\begin{array}{c}\text { Sekonder } \\
\text { Osteoporoz }\end{array}$ \\
\hline Yok & 1 & 1 & 1 \\
$\begin{array}{l}\text { Vertebra } \\
\text { Kırı̆̆ı }\end{array}$ & 3 & 2 & 1 \\
$\begin{array}{l}\text { Diğer Kırık } \\
\text { (Ön Kol, Kol) }\end{array}$ & 1 & - & - \\
$\begin{array}{l}\text { Vertebra }+ \\
\text { Diğer Kırık }\end{array}$ & 2 & - & 1 \\
\hline
\end{tabular}

Tablo 3. Kalça Kırı̆̆ı Geçiren Hastaların Kırık Analizi

\begin{tabular}{lcccc}
\hline & Cinsiyet & $\begin{array}{c}\text { Kırık Geçirilen } \\
\text { Yaş }\end{array}$ & $\begin{array}{c}\text { Vertebral Kırık } \\
\text { Sayısı }\end{array}$ & $\begin{array}{c}\text { Diğer } \\
\text { Kırık } \\
\text { (Var/Yok) }\end{array}$ \\
\hline $\mathbf{1}(\mathbf{E x})$ & Kadın & 76 & 6 torakal & - \\
$\mathbf{2}(\mathbf{E x})$ & Kadın & 81 & 2 torakal & var \\
$\mathbf{3}$ & Kadın & 63 & - & var \\
$\mathbf{4}$ & Kadın & 76 & 3 torakal & - \\
$\mathbf{5}$ & Kadın & 65 & 8 torakal & var \\
$\mathbf{6}$ & Kadın & 52 & - & - \\
$\mathbf{7}$ & Kadın & 55 & 3 torakal & - \\
$\mathbf{8}$ & Erkek & 73 & 3 torakal & - \\
$\mathbf{9}$ & Erkek & 56 & - & - \\
$\mathbf{1 0}$ & Erkek & 59 & 2 torakal & - \\
$\mathbf{1 1}(\mathbf{E x})$ & Kadın & 85 & 4 torakal & - \\
$\mathbf{1 2}$ & Kadın & 78 & - & var \\
$\mathbf{1 3}$ & Erkek & 63 & 4 torakal,2 lomber & \\
\hline
\end{tabular}

\section{Tartışma}

Kalça kırı̆̆ı osteoporozda mortalite ve morbiditeyi olumsuz yönde etkileyen ve sosyal maliyete neden olan ciddi bir sonuçtur (11). Biz çalışmamızda osteoporoz tanılı hastalardaki yaklaşık on y1llık sürede karşılaştıkları kalça kırığı sıklığını geriye dönük olarak değerlendirdik. Osteoporoz tanılı hastalarda kalça kırığı oranını \%8.84, kalça kırığı sonucunda ölüm oranını \%2.04 olarak bulduk. 
Günümüzde osteoporoz tanıs1, dual enerji Xray absorbsiyometri yöntemi (DXA) ile ölçülen kemik mineral yoğunluğu (KMY) ile konulmaktadır. $\mathrm{Bu}$ değerlendirmede lomber omurga (L1-L4) ve kalça (boyun, trokanter ve ward üçgeni ) kullanılır. Dünya Sağlık Örgütü'nün önerdiği şekilde kemik dansitesi ortalamas1 2.5 standart deviasyon (SD) altında olanlar osteoporoz olarak değerlendirilir (1). Çalışmamıza kliniğimizde takipli kemik dansitesi ortalamas1 2.5 standart deviasyon (SD) altında olan osteoporoz tanıl1 147 hasta dâhil edilmiştir.

Osteoporoza bağlı kırıklar yaygın olarak görülür (1). Osteoporoz kırıklar ile komplike hale gelene kadar genellikle sessizdir (1). Osteoporoza bağlı kırıkların (kalça, vertebra, ön kol, kol) riski dünyada dikkat çekici bir şekilde artmaktadır (12). Osteoporoza bağlı kırık insidansı ülkeler arasında farklıdır (12). Kalça kırı̆̆ı insidansının en yüksek olduğu ülkeler İskandinav ülkeleridir. Kalça kırığı siklığının siyahlara ve Asya toplumlarına oranla beyazlarda daha yüksek olduğu bildirilmiştir (13).Türkiye kalça kırık riski açısından düşük riske sahip ülkeler arasindadır (14).

Dünya Sağlık Örgütü 2008 yılında kırık risk değerlendirmesinde Kırık Risk Değerlendirme Ölçeği'ni "Fracture Risk Asssesment Tool" (FRAX) önermiştir. FRAX bilgisayar programı postmenopozal kadın ve 40 yaşından yaşlı erkekte validite edilmiştir. FRAX, 10 yıllık osteoporotik kırık olasılığını (kalça, omurga, kol veya ön kol) ve 10 yıllık kalça kırığı olasılığını verir (11). FRAX, Tüzün ve ark. tarafından Türkiye için FRACTURK olarak uyarlanmıştır. Buna göre 50 yaşından sonra Türk kadınları için, her yedi kişiden birinin kalan ömürleri boyunca bir kalça kırığı yaşayacağı gösterilmiştir (10).

Kalça kırığı riski yaşla birlikte artar ve kadınlarda daha sık görülür (15). Ulusal verilere göre osteoporoz ile ilişkili kalça kırığı oranları 50-64 yaş arasında her iki cinsiyette benzer iken, 64 yaş üzerinde kadınlarda daha fazla olduğu bildirilmiştir (10). Tanriöver ve ark. yaptıkları çalışmada osteoporoza bağlı kalça kırı̆̆ 1 geçiren hastaların yaş ortalamasının 74.2 ve \% 72'sinin kadın olduğunu bildirmişlerdir (16). Bizim çalışmamızda osteoporoza bağlı kalça kırığ geçiren hastaların yaş ortalaması 67,85 $\pm 10,88^{\prime}$ idi ve \%69.23'ü kadındı. Sonuçlarımız literatürle benzerdi.

Sucuoğlu ve Koyuncu' nun yaptığı ve 1303 osteoporoz hastasının incelendiği çalışmada, osteoporoza bağlı gelişen kalça kırığının erkeklerde $\% \quad 6.83$ oranında olduğunu bildirmişlerdir (17). Bizim çalışmamızda erkeklerde geçirilen kalça kırığı oranı \%17.39 bulunmuştur. $\mathrm{Bu}$ farklılığın örneklem boyutundaki farklılıktan kaynaklandığı düşünülmüştür.

Osteoporoza bağlı kalça ve vertebra kırıkları sonras1 bir y1llik mortalite \% 20'ler civarındadır (13). Ostoporoza bağlı kırıklar arasında kalça kırığı mortalite ve morbiditenin en büyük sorumlusudur. Osteoporoza bağl1 vertebra kırıkları genellikle sessizdir bununla birlikte tek vertebra kırığının olması kalça kırık riskini 5 kat arttırdığ 1 bilinmektedir (1). Japonya' da yapılan iki çalışmada vertebra kırığı ile birlikte kalça kırığı olan hastalarda mortalite ve morbiditenin daha yüksek olduğu savunulmuştur $(18,19)$. Bizim çalışmamızda kalça kırığı saptanan 13 hastanın 10'unda vücutta gelişen başka bir kırık öyküsü vardı. $\mathrm{Bu} 10$ hastanın 9'unda ise daha önce geçirilmiş osteoporoza bağlı vertebral kırık öyküsü mevcuttu. Çalışmamızdaki, osteoporotik kalça kırığına bağlı ölen 3 hastamız birden fazla vertebral kırığa sahipti. Osteoporoz takip ve tedavisini planlarken belirgin klinik semptom vermeden seyredebilen vertebral kırık varlığını iyi araştırmak gerektiği düşünülmüştür.

$\mathrm{Bu}$ çalışmaya dâhil edilen hastaların osteoporoz tedavisi alıp almadığı, ilaç kullanıyorsa hangi ilaçları kullandığı ve ne kadar süredir kullandığı sorgulanmadı. Kalça kırığı üzerine ilaç kullanımının etkisinin değerlendirilmemiş olması çalışmamızın eksik yönüdür. Bunun yanında osteoporoz tanıs1 almış hastaların yaklaşık on yıllık takipleri sonucunda karşılaşacakları kalça kırığı olası riskinin müspet sonuçlarını vermesi çalışmamızın güçlü yanıdır. 
Osteoporoz, toplumda yaygın görülen önemli bir halk sağlığı sorunudur. Osteoporoza bağ 11 kalça kırıkları önemli bir mortalite ve morbidite sebebidir. Bu nedenle osteoporoza bağlı kalça kırıklarını önlemeye yönelik risk gruplarının belirlenerek tedbirlerin alınmasına önem verilmelidir.

Ortalama yaşam süresinin uzamasına bağlı olarak osteoporoz ve osteoporoz nedenli kırık görülme oranlarının artması beklenmektedir.
Ülkemiz kalça kırığı beklentisinin az olduğu ülkelerden biridir. $\mathrm{Bu}$ sonuç yeterli takip ve çalışmanın yapılmamasından, kayıt/veri eksikliğinden kaynaklanmış olabilir.

\section{Sonuc}

Osteoporoz hastalarındaki kalça kırığı sıklığ ve buna bağlı ölümlerle ilgili verilerimizin mevcut veri tabanına katk1 sağlayacağı ve

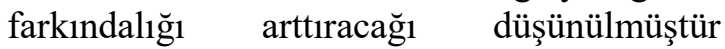

\section{KAYNAKLAR}

1. Cosman F, de Beur S J, LeBoff M S, Lewiecki EM, Tanner B, Randall S, Lindsay R. Clinician's guide to prevention and treatment of osteoporosis. Osteoporos Int 2014; 25: 2359-81

2. Cooper C, Campion G, Melton LJ 3rd. Hip fractures in the elderly: a world-wide projection. Osteoporosis Int. 1992 ;2(6):285-9.

3. Cummings S, Melton L. Epidemiology and outcomes of osteoporotic fractures. Lancet. 2002 18;359:1761-7.

4. Osteoporosis: Assessing the risk of fragility fracture Short clinical guideline - CG146 Evidence and recommendations Nice Clinical Guideline 2012.

5. Watts NB, Bilezikian JP, Camacho PM, Greenspan SL, Harris ST, Hodgson SF, Kleerekoper M, Luckey MM, McClung MR, Pollack RP, Petak SM.American association of clinical endocrinologists medical guidelines for clinical practice for the diagnosis and treatment of postmenopausal osteoporosis. Endocr Practice 2010;16:1-37.

6. Hansen L, Mathiesen AS, Vestergaard P, Ehlers LH, Petersen KD. A health economic analysis of osteoporotic fractures: who carries the burden? Arch Osteoporos. 2013;8: 126.

7. Poor G, Atkinson EJ, O'Fallon WM, Melton III LJ. Determinants of reduced survival following hip fractures in men. Clin Orthop Relat Res. 1995;319:260

8. Kaya T. Kemikte yoğunluk azlığı, metabolik ve hormonal kemik hastalıkları. İçinde. Kaya $\mathrm{T}$, editör. Kas iskelet-yumuşak doku radyolojisi. Nobel Güneş Tıp Kitabevi, Bursa; 2008:193-214.

9. Gullberg B, Johnell O, Kanis JA. World-wide projections for hip fracture. Osteoporos Int 1997;7:407-13.

10. Tuzun S, Eskiyurt N, Akarirmak U, Saridogan M, Senocak M, Johansson H, et al. Incidence of fracture and prevalance of osteoporosis in

Turkey: the Fracturk study. Osteoporos Int. 2012;23: 949-55.

11. Kanis JA, Johnell O, Oden A, Johansson H, McCloskey EV. FRAX ${ }^{\mathrm{TM}}$ and the assessment of fracture probability in men and women from the UK. Osteoporos Int. 2008;19:385-97.

12. Kanis JA, Johnell O, De Laet C, Jonsson B, Oden A, Ogelsby AK.International variations in hip fracture probabilities: implications for risk assessment. J Bone Miner Res. 2002;17:1237-44.

13. Meray J, Peker Ö. Osteoporozda Tanı ve Tedavi. İstanbul: Gelanos Yayınevi; 2012. p.7147.

14. Elffors I, Allander E, Kanis JA, Gullberg B, Johnell $\mathrm{O}$, Dequeker $\mathrm{J}$ et al. The variable incidence of hip fracture in Southern Europe: the Medos Study. Osteoporos Int .1994;4:253263.

15. Duman AE, Güven GS, Gürlek A. Erkek osteoporozu. Hacettepe Tip Dergisi 2005;36: 175-83.

16. Tanriover $\mathrm{MD}, \mathrm{Oz} \mathrm{SG}$, Tanriover A, Kilicarslan A, Turkmen E, Guven GS, Saracbasi O, Tokgozoglu M, Sozen T. Hip fractures in a developing country: osteoporosis frequency, predisposing factors and treatment costs. Arch Gerontol Geriatr. 2010;50:13-8.

17. Sucuoğlu H, Koyuncu H. Erkek osteoporoz hastalarının yaş, sinıflandırma ve kırık varlığına göre dağılımı. İstanbul Med J.2017; 18: $13-7$

18. Ha YC, Baek JH, Ko YB, Park SM, Song SH. High mortality and poor morbidity after hip fracture in patients with previous vertebral fractures. J Bone Miner Metab. 2015;33:54752.

19. Imai $\mathrm{N}$, Endo $\mathrm{N}$, Hoshino $\mathrm{T}$, Suda $\mathrm{K}$, Miyasaka D, Ito T. Mortality after hip fracture with vertebral compression fracture is poor. $\mathbf{J}$ Bone Miner Metab. 2016;34:51-4. 